\title{
Commentary: Neural Changes Associated with Treatment Outcome in Children with Externalizing Problems
}

\author{
Timothy R. Rice* \\ Icahn School of Medicine at Mount Sinai, New York, NY, USA
}

Keywords: emotion regulation, defense mechanisms, oppositional defiant disorder, executive function, psychoanalytic therapy

OPEN ACCESS

Edited by:

Paul Croarkin,

Mayo Clinic, USA

Reviewed by:

Ernest Pedapati,

Cincinnati Children's Hospital

Medical Center, USA

Luke Aaron Schneider,

University of Adelaide, Australia

Natasha Radhu,

University of Toronto, Canada

Jeylan Close,

University of Michigan, USA

${ }^{*}$ Correspondence:

Timothy R. Rice

timothy.rice@mssm.edu

Specialty section:

This article was submitted to Neuroimaging and Stimulation,

a section of the journal

Frontiers in Psychiatry

Received: 24 June 2016 Accepted: 13 September 2016 Published: 26 September 2016

Citation:

Rice TR (2016) Commentary: Neural Changes Associated with Treatment Outcome in Children with Externalizing Problems.

Front. Psychiatry 7:161. doi: 10.3389/fpsyt.2016.00161
A commentary on

Neural changes associated with treatment outcome in children with externalizing problems by Woltering S, Granic I, Lamm C, Lewis MD. Biol Psychiatry (2011) 70:873-9. doi:10.1016/j. biopsych.2011.05.029

\section{INTRODUCTION}

In a 2011 study published in the journal Biological Psychiatry, Steven Woltering and colleagues demonstrate that children with externalizing behaviors who respond to cognitive behavioral therapy show electroencephalogram-defined neural markers of improved self-regulation (1). In this commentary, I review this study and the rationale for my proposal that children with externalizing behaviors who respond to psychoanalytic psychotherapy may also show similar neural markers of improved self-regulation. The intent is to help psychoanalytically oriented providers, who may have reservations toward evidence-based medicine and mainstream psychiatric care, to see the value of a brain-based dimensional model of recovery and of hypothesis testing to create an evidence base for practice.

\section{DEFINITIONS AND APPROACHES}

From a descriptivist perspective, childhood externalizing behaviors are negative behaviors that are directed toward the external environment (2). From the original psychoanalytic perspective that coined the term, these behaviors are the products of children's tendencies to externalize components of developing personality structures onto the external environment (3-5). To a contemporary psychoanalytic perspective, this implicit process serves to reduce internal anxiety and regulate negative affect (6), a component of implicit emotion regulation $(7,8)$.

While behavioral therapies commonly promote self-regulation through (1) parent management training interventions to reward prosocial behaviors and to extinguish negative behaviors and (2) improving executive functioning through skills training and coaching, psychoanalytic approaches promote emotion regulation through communicating to the child the self-protective meanings of negative behaviors. This intervention alongside developmental help scaffolds the child's development of alternative emotion regulation capacities (8). As both behavioral 
therapy and child psychoanalytic psychotherapy target self-regulation through the related constructs of emotion regulation and "hot" executive functions (9), the both modalities' successful outcomes may show similar underlying neural changes.

\section{NEURAL CORRELATES OF RESPONSE TO COGNITIVE BEHAVIORAL THERAPY}

Woltering and colleagues' study provides a model for exploring this hypothesis. This study recruited 140 children aged 8-12 from outpatient treatment agencies with scores on the externalizing scale of the Child Behavior Checklist [CBCL; (10)] within the clinical or borderline-clinical range. These children all received electroencephalography (EEG) while performing a test of selfregulation termed a go/no-go task (11).

All children then engaged in an evidence-based cognitive behavioral therapy program with an integrated parent management training ["Stop Now and Plan"; (12)]. This program entailed 14 weekly 3 -h group sessions consisting of parent management training and child interventions. Cognitive restructuring, problem-solving, role-playing, social and token reinforcements, and generalization activities were provided. Groups were led by psychology trainees, social workers, and childcare workers. Supervisors assessed treatment fidelity.

The Child and Adolescent Functional Assessment Scale [CAFAS; (13)] was applied pre- and post-intervention. A preand post-intervention decrease of 20 points or more defined a treatment response.

Seventy-one of the original 140 participants completed the treatment with usable data. Fifty-five percent (39 completers) were treatment non-responders, and 45\% (32 completers) were responders. Non-responders, responders, and 24 age-matched children recruited from the community then repeated the go/ no-go task under EEG.

Treatment responders, but not non-responders, showed reductions in posttreatment relative to pretreatment EEG in needed cortical resources to regulate impulsive behavior during the go/no-go task. Specific findings included, a reduction in the magnitude of the N2 component of the event-related potential (ERP), a defined waveform associated with inhibition of prepotent responses $(14,15)$. This represents reduced cortical resource requirements for response inhibition, a key executive function. Source space analysis, or analyses to determine the anatomical region from which EEG signals generate (16), pointed to the prefrontal regions associated with self-regulation.

This study suggests that successful as opposed to unsuccessful treatment normalizes aberrant biomarkers of executive functioning in children with externalizing behaviors and are associated with improved executive function performance on a go/no-go task.

\section{EVENT-RELATED POTENTIALS, EXECUTIVE FUNCTIONS, AND EMOTION REGULATION}

The study of ERPs is an ideal neurobiological modality to bridge the theoretical executive function and emotion regulation literature. Several studies examine ERPs in children with externalizing behaviors as both a neural correlate of emotion regulation (11, $17-19)$ and of executive functioning $(1,20)$. This dual conceptualization suggests that psychotherapies that target executive function deficits (1) and emotion regulation deficits (19) operate on the same neural system. This facilitates a harmonization of executive skills coaching and other cognitive behavioral interventions with psychoanalytic psychotherapies in addressing externalizing behaviors: Contemporary psychoanalytic psychotherapy practices are hypothesized to target the implicit emotion regulation system (7).

\section{EXECUTIVE FUNCTIONS, EMOTION REGULATION, AND PSYCHOANALYTIC PSYCHOTHERAPY}

Contemporary child psychoanalytic psychotherapy involves the interpretation of children's defenses against unwelcome affects $(6,21-23)$. This experience-near technique targets children's guarding against experiencing painful feelings through automatic recourse to externalizing behaviors. This style is an implicit emotion regulation strategy. Implicit emotion regulation (24, 25) shares neuroanatomical correlates with those of the "hot" executive functions (9). "Hot" denotes automaticity, rapidity, and colored by emotion and include ventral prefrontally mediated automatic and effortless modulation of limbic and visceromotor areas (26). These areas match those in Woltering et al's study that were shown to be implicated in responsiveness to behavioral interventions. The sharing of a functional neural system target with behavioral interventions implies what clinicians and theoreticians [e.g., Ref. (27)] have long proposed: all modes of psychotherapy hold much more in common than in difference.

\section{EXPLORING THIS HYPOTHESIS AND CONCLUSION}

An 8-week manualized psychoanalytic approach to children aged 6-12 with externalizing behaviors organized around defense analysis (28) is under initial study. This trial may be eligible for evidence testing through neurobiological markers, including ERPs as well as functional magnetic imaging (fMRI). Child psychoanalytic psychotherapy stands to benefit from such study.

\section{AUTHOR CONTRIBUTIONS}

The author confirms being the sole contributor of this work and approved it for publication. 


\section{REFERENCES}

1. Woltering S, Granic I, Lamm C, Lewis MD. Neural changes associated with treatment outcome in children with externalizing problems. Biol Psychiatry (2011) 70:873-9. doi:10.1016/j.biopsych.2011.05.029

2. Liu J. Childhood externalizing behavior: theory and implications. JChild Adolesc Psychiatr Nurs (2004) 17:93-103. doi:10.1111/j.1744-6171.2004. tb00003.x

3. Freud A. Normality and Pathology in Childhood. London, UK: Hogarth Press (1965).

4. Furman E. Transference and externalization in latency. Psychoanal Study Child (1980) 35:267-84.

5. Novick J, Kelly K. Projection and externalization. Psychoanal Study Child (1970) 25:69-95.

6. Hoffman L. Do children get better when we interpret their defenses against painful feelings? Psychoanal Study Child (2007) 62:291-313.

7. Rice TR, Hoffman L. Defense mechanisms and implicit emotion regulation: a comparison of a psychodynamic construct with one from contemporary neuroscience. JAm Psychoanal Assoc (2014) 62:693-708. doi:10.1177/ 0003065114546746

8. Rice TR. Commentary: the neural bases of emotion regulation. Front Psychol (2016) 7:476. doi:10.3389/fpsyg.2016.00476

9. Rice T. Commentary: how child's play impacts executive function-related behaviors. Front Psychol (2016) 7:968. doi:10.3389/fpsyg.2016.00968

10. Achenbach T. Manual for the Child Behavior Checklist/4-18 and 1991 Profile. Burlington, VT: University of Vermont, Department of Psychiatry (1991).

11. Stieben J, Lewis MD, Granic I, Zelazo PD, Segalowitz S, Pepler D. Neurophysiological mechanisms of emotion regulation for subtypes of externalizing children. Dev Psychopathol (2007) 19:455-80. doi:10.1017/ S0954579407070228

12. Earlscourt Child and Family Centre. SNAP ${ }^{\mathrm{TM}}$ Children's Group Manual. Toronto: Earlscourt Child and Family Centre (2001).

13. Hodges K, Wong MM. Psychometric characteristics of a multidimensional measure to assess impairment: the Child and Adolescent Functional Assessment Scale. J Child Fam Stud (1996) 5:445-67. doi:10.1007/BF02233865

14. Falkenstein M, Hoormann J, Hohnsbein J. ERP components in Go/Nogo tasks and their relation to inhibition. Acta Psychol (Amst) (1999) 101:267-91. doi:10.1016/S0001-6918(99)00008-6

15. Folstein JR, Van Petten C. Influence of cognitive control and mismatch on the N2 component of the ERP: a review. Psychophysiology (2008) 45:152-70. doi:10.1111/j.1469-8986.2007.00602.x

16. Michel CM, Murray MM, Lantz G, Gonzalez S, Spinelli L, Grave de Peralta R. EEG source imaging. Clin Neurophysiol (2004) 115:2195-222. doi:10.1016/j. clinph.2004.06.001
17. Granic I, Meusel LA, Lamm C, Woltering S, Lewis MD. Emotion regulation in children with behavior problems: linking behavioral and brain processes. Dev Psychopathol (2012) 24:1019-29. doi:10.1017/S0954579412 00051X

18. Lewis MD, Lamm C, Segalowitz SJ, Stieben J, Zelazo PD. Neurophysiological correlates of emotion regulation in children and adolescents. J Cogn Neurosci (2006) 18:430-43. doi:10.1162/089892906775990633

19. Lewis MD, Granic I, Lamm C, Zelazo PD, Stieben J, Todd RM, et al. Changes in the neural bases of emotion regulation associated with clinical improvement in children with behavior problems. Dev Psychopathol (2008) 20:913-39. doi:10.1017/S0954579408000448

20. Albrecht B, Banaschewski T, Brandeis D, Heinrich H, Rothenberger A. Response inhibition deficits in externalizing child psychiatric disorders: an ERP-study with the Stop-task. Behav Brain Funct (2005) 1:22. doi:10.1186/1744-9081-1-22

21. Becker TE. On latency. Psychoanal Study Child (1974) 29:3-11.

22. Bornstein B. Clinical notes on child analysis. Psychoanal Study Child (1945) $1: 151-66$.

23. Bornstein B. The analysis of a phobic child-some problems of theory and technique in child analysis. Psychoanal Study Child (1949) 3:181-226.

24. Etkin A, Büchel C, Gross JJ. The neural bases of emotion regulation. Nat Rev Neurosci (2015) 16:693-700. doi:10.1038/nrn4044

25. Gyurak A, Gross JJ, Etkin A. Explicit and implicit emotion regulation: a dual-process framework. Cogn Emot (2011) 25:400-12. doi:10.1080/026999 31.2010.544160

26. Zelazo PD, Carlson SM. Hot and cool executive function in childhood and adolescence: development and plasticity. Child Dev Perspect (2012) 6:354-60. doi:10.1111/j.1750-8606.2012.00246.x

27. Damasio A. Descartes' Error: Emotion, Reason, and the Human Brain. New York, NY: Grosset/Putnam (1994).

28. Hoffman L, Rice T, Prout T. Manual for Regulation-Focused Psychotherapy for Children with Externalizing Behaviors (RFP-C): A Psychodynamic Approach. New York, NY: Routledge (2015).

Conflict of Interest Statement: The author declares that the research was conducted in the absence of any commercial or financial relationships that could be construed as a potential conflict of interest.

Copyright $\odot 2016$ Rice. This is an open-access article distributed under the terms of the Creative Commons Attribution License (CC BY). The use, distribution or reproduction in other forums is permitted, provided the original author(s) or licensor are credited and that the original publication in this journal is cited, in accordance with accepted academic practice. No use, distribution or reproduction is permitted which does not comply with these terms. 